\title{
ESTUDO DE LITERATURA DOS CENTROS DE DISTRIBUIÇÃO DE CROSSDOCKING: Analise da gestão da cadeia de suprimentos e os problemas de sequenciamento e roteamento
}

\author{
Priscila Mara Cota (FUNCESI) priscila.cota@ funcesi .br \\ Willian Almeida Araújo (FUNCESI) william_a_almeida@ hotmail.com \\ Jamile Souza Santos (FUNCESI) ajamilesantos@gmail.com \\ Denizar de Souza Martins (FUNCESI) souza.denis@ hotmail.com \\ Ana Flávia domingos Aleixo (FUNCESI) aninha_aleixo@rocketmail.com
}

\section{Resumo}

Devido à crescente competitividade de mercado, é indispensável para as empresas a utilização de técnicas que visam melhorar o sistema de produção, distribuição e logística. Assim, as empresas passaram a trabalhar com baixo volume de estoque e maior frequência de entregas, reduzindo os custos operacionais. A cultura de um grande estoque é ultrapassada, devido aos elevados gastos que isso possa acarretar. Uma das soluções para se resolver esse problema é o crossdocking, que é um sistema de distribuição onde a mercadoria recebida não passa pelo processo de estocagem. Diante disto, o presente trabalho busca descrever e analisar as técnicas de crossdocking em um estudo de revisão de literatura - que tem como objetivo a utilização dos centros de distribuição para a redução dos custos com estocagem, agilizar as entregas e suprir a demanda de produtos - e discutir a maneira com que estão sendo utilizadas na indústria, além de apresentar as vantagens e desvantagens deste processo. Os benefícios da utilização do crossdocking são inúmeros, entre eles podemos citar o menor tempo e custo logístico, redução do lead time e do capital de giro e a satisfação do cliente. O problema foi abordado ratando casos da cadeia de produção, discutindo três diferentes problemas considerando o sequenciamento, o roteamento dos veículos e a integração da rede de suprimentos.

Palavras-Chaves: (Crossdocking. Cadeia de produção. Sequenciamento. Roteamento)

\section{Introdução}

É notável como a concorrência está cada vez mais forte, pelo mundo que vivemos com as tecnologias a informação cada vez mais rápida e mais fácil de serem obtidas, as indústrias veem necessidade de melhorar em todos os aspectos e dentre esses, a logística está entre os 
principais itens. Métodos de distribuição foram criados com objetivo de diminuir o custo e aumentar a eficiência como um todo.

Com o passar dos anos as grandes indústrias focaram seus esforços em algumas atitudes dentre elas a logística, e com isso foram se criando estudos de formas diferentes e eficazes de se fazer transporte. Devido a crescente competitividade de mercado, é indispensável para as empresas a utilização de técnicas que visam melhorar o sistema de produção, distribuição e logística. Assim, as empresas passaram a trabalhar com baixo volume de estoque e maior frequência de entregas, reduzindo os custos operacionais.

A cultura de um grande estoque é ultrapassada, devido aos elevados gastos que isso pode acarretar. Uma das soluções para se resolver esse problema, é o crossdocking, pois segundo Ballou (2006, p.377)“os armazéns podem trabalhar exclusivamente no recebimento e embarque, eliminando as atividades de estocagem e separação de pedidos. Passam a ser conhecidos como os armazéns de trânsito (crossdocks)," que é um sistema de distribuição onde a mercadoria recebida não passa pelo processo de estocagem. Ao invés disto, a mercadoria já é preparada para o processo de entrega. Diferentemente do processo de entrega usual, as entregas através do crossdocking são feitas em menor volume e maior rapidez, o que é um benefício para o cliente e para o fornecedor.

Com a implementação desse sistema há um impacto na sociedade beneficiando a mobilidade urbana em grandes metrópoles e até em pequenas cidades, diminuindo o fluxo de grandes veículos grandes e possibilitando operações logísticas em locais remotos.

Em virtude da baixa quantidade de exemplares e estudos sobre crossdocking em cidades brasileiras, nota-se a necessidade da produção de novas fontes de consulta de forma a descrever as práticas e principais formas de utilização da técnica, que reproduzam a sua utilização no dia a dia de um estabelecimento. Com esse trabalho pretendemos mostra a importância do crossdocking bem como os temas que se ligam a ele. Sendo abordados os principais conceitos, e a junção do que a literatura nos oferece e a apresentações de situações de utilização. 


\section{Referencial Teórico}

As empresas de modo geral começaram a olhar a logística com muito mais atenção desde que entenderam que ela influencia diretamente no custo e na competitividade da organização. E também quando entenderam como esta pode ser complexa e com a várias lacunas a serem analisadas. Métodos foram criados, e o estoque grande não é mais tão interessante para alguns, pois existem muitas perdas associadas. E assim surgem algumas técnicas interessantes a serem exploradas. Esse artigo trata em especial do crossdocking, como uma nova forma de ver os centros de distribuição. Esse artigo primeiramente apresenta um breve referencial teórico sobre o tema e posteriormente apresenta situações em que o crossdocking pode ser aplicado, sendo uma nova fonte de pesquisa.

\subsection{Cadeia de Suprimento}

Segundo Slack, Chambers e Johnston (2009, p. 144) "Nenhuma operação existe isoladamente. Todas as operações fazem parte de uma rede maior, interconectada com outras operações. Essa rede de suprimento inclui fornecedores e clientes”. Já Ballou (2006) afirma que a cadeia de suprimentos refere-se a um conjunto de funções como transportes, controle de estoques, processamento de pedidos, armazenagem, entre outros, que se reproduzem incontáveis vezes no decorrer do canal por onde são transformadas as matérias-primas em produtos, que por sua vez se agrega valor sendo destinados ao consumidor. De acordo com Slack, Chambers e Johnston (2009), a cadeia de suprimentos pode ser classificada em três etapas, fornecedores, a operação produtiva e os consumidores, conforme apresentado na Figura 1.

Figura 1- Cadeia de suprimento

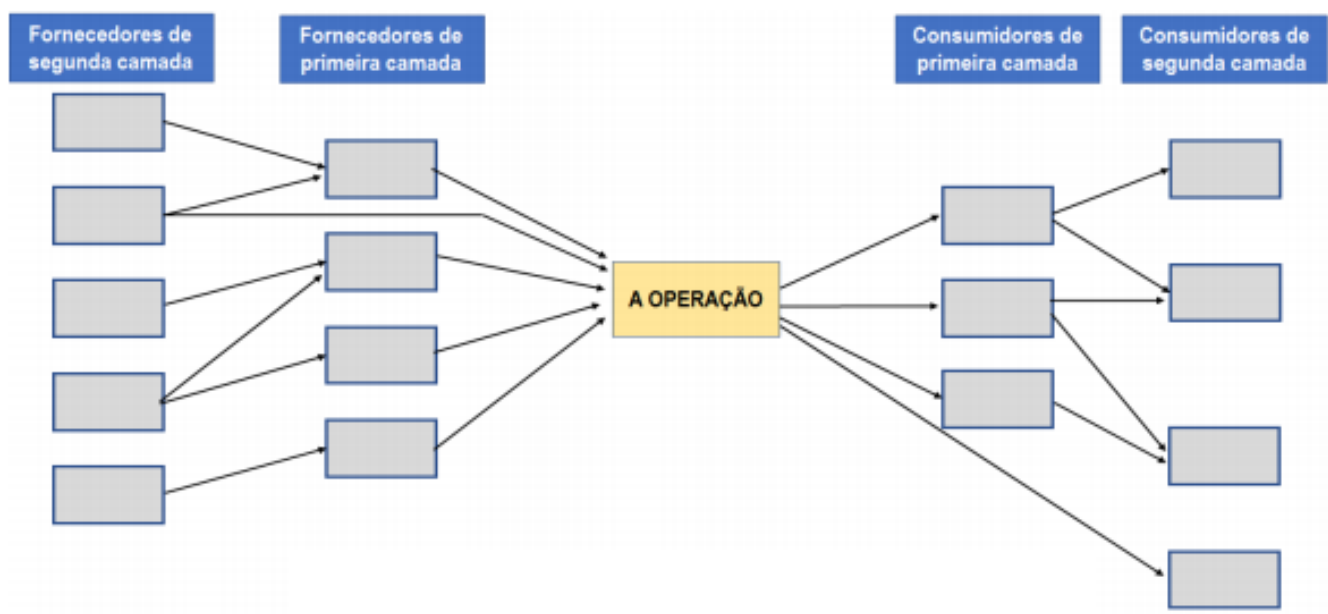

Fonte: Adaptado de Slack, Chambers e Johnston (2009, p. 146) 
A partir da Figura 1 é possível verificar uma rede de suprimento. De acordo com Slack, Chambers e Johnston (2009) uma perspectiva de rede de suprimento significa definir a operação no contexto de todas as outras operações com as quais interage, algumas das quais são seus fornecedores e outras, seus clientes. Dentro dessa rede pode haver vários fluxos diferentes em ambas as direções. Fluxos de materiais, peças, informações, ideias e às vezes pessoas, tudo flui pela rede de relações cliente-fornecedor formada por essas operações. No lado do fornecimento, uma operação tem seus fornecedores de peças ou informações ou serviços. Esses fornecedores têm seus próprios fornecedores, que, por sua vez, também têm fornecedores, e assim por diante. No lado da demanda, a operação tem clientes. Esses clientes podem não ser os usuários finais dos produtos ou serviços da operação; podem ter o seu próprio conjunto de clientes. É importante discutir a cadeia de suprimento para que se possa entender o conceito de centro de distribuição, que existe para simplificar os fluxos dentro dessa cadeia que podem ser complexos.

\subsection{Centros de Distribuição}

Segundo Farah (2002, p.44), os Centros de Distribuição são "instrumentos que podem viabilizar de forma competitiva o fluxo de mercadorias vindas dos fabricantes, até os seus diversos graus de capilaridade distributiva". Ou seja, são armazéns localizados em pontos estratégicos (como cidades distantes dos centros de produção), com a finalidade de receber os produtos de seus fornecedores e encaminhá-los até os seus clientes de maneira mais rápida.

De acordo com Souza (2010), os Centros de Distribuição possuem as seguintes etapas:

- Recebimento: Os produtos são enviados pelos fornecedores até o centro de distribuição e os produtos cadastrados em um sistema, para que haja controle de estoque;

- Movimentação: É o processo de transferência dos produtos do seu local de recebimento até a armazenagem;

- Armazenagem: É a etapa em que os produtos ficam temporariamente estocados, até que sejam vendidos e implica em um dos maiores custos de todo o processo produtivo;

- Separação/coleta dos pedidos: Os produtos são retirados do local armazenado e preparados para o envio, de acordo com o pedido dos clientes; 
- Expedição: Os itens são revisados, para que não seja entregue um produto errado ao cliente. São feitas as pesagem das cargas, a validação dos pedidos e a emissão dos documentos necessários.

Os Centros de Distribuição são uma forma de redução dos custos, pois centralizam os estoques, possibilitam maior controle dos processos, agilizam as entregas e proporcionam um atendimento de qualidade, um centro de distribuição pode ser verificado na Figura 2.

Figura 2: Centro de distribuição

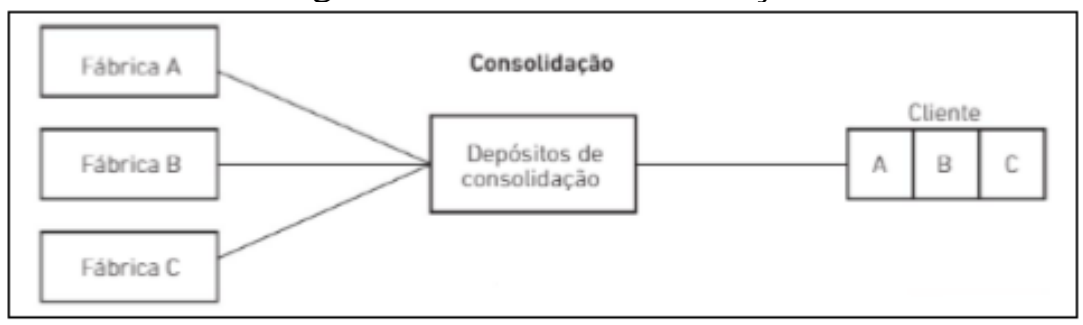

Fonte: Bowersox et al (2014, p.230)

A partir da Figura 2 pode se verificar que chegam cargas ao centro vindas de vários fornecedores, no centro essa carga é organizada/combinada e encaminhada a um cliente, evitando assim várias entregas ao mesmo cliente. O que reduz a complexidade do fluxo de transporte. Entretanto é preciso um espaço para armazenar e organizar essa mercadoria, sendo assim os centros de distribuição possuem a característica de serem grandes.

\subsection{Centros de distribuição de Crossdocking (CCD)}

O centro de distribuição de crossdocking é uma abordagem que elimina ou reduz significativamente duas funções custosas dos centros tradicionais de distribuição que são a estocagem e coleta dos produtos. Para isso, um Centro de Crossdocking (CCD) funciona com estoque limitado ou, se possível, nulo. Esses conceitos são baseado em uma logística inteligente onde a carga chega ao centro e logo após ser descarregada dos caminhões vindos dos diversos fornecedores é carregada nos caminhões para serem entregues aos clientes, sem a necessidade de permanecerem no CCD. Mas para que isso aconteça que tem haver confiabilidade de entregas e de partidas dos caminhões, o que significa que a cadeia de distribuição tem que trabalhar com exatidão dos três componentes, fornecedores, empresa e clientes. O centro de distribuição de crossdocking, encontra-se apresentado na Figura 3. 
Os CCDs apresentam docas de entrada e docas de saída. As docas de entrada são portas que recebem e descarregam os caminhões vindos dos diversos fornecedores e as docas de saída, são as portas que recebem e carregam os caminhões que serão encaminhados aos clientes. Quanto mais docas o centro possui maior é a sua capacidade de atendimento, em algumas situações as docas são docas mistas que podem ser compartilhadas para descarregamento e carregamento de caminhões.

Figura 3 - Modelo de distribuição Crossdocking

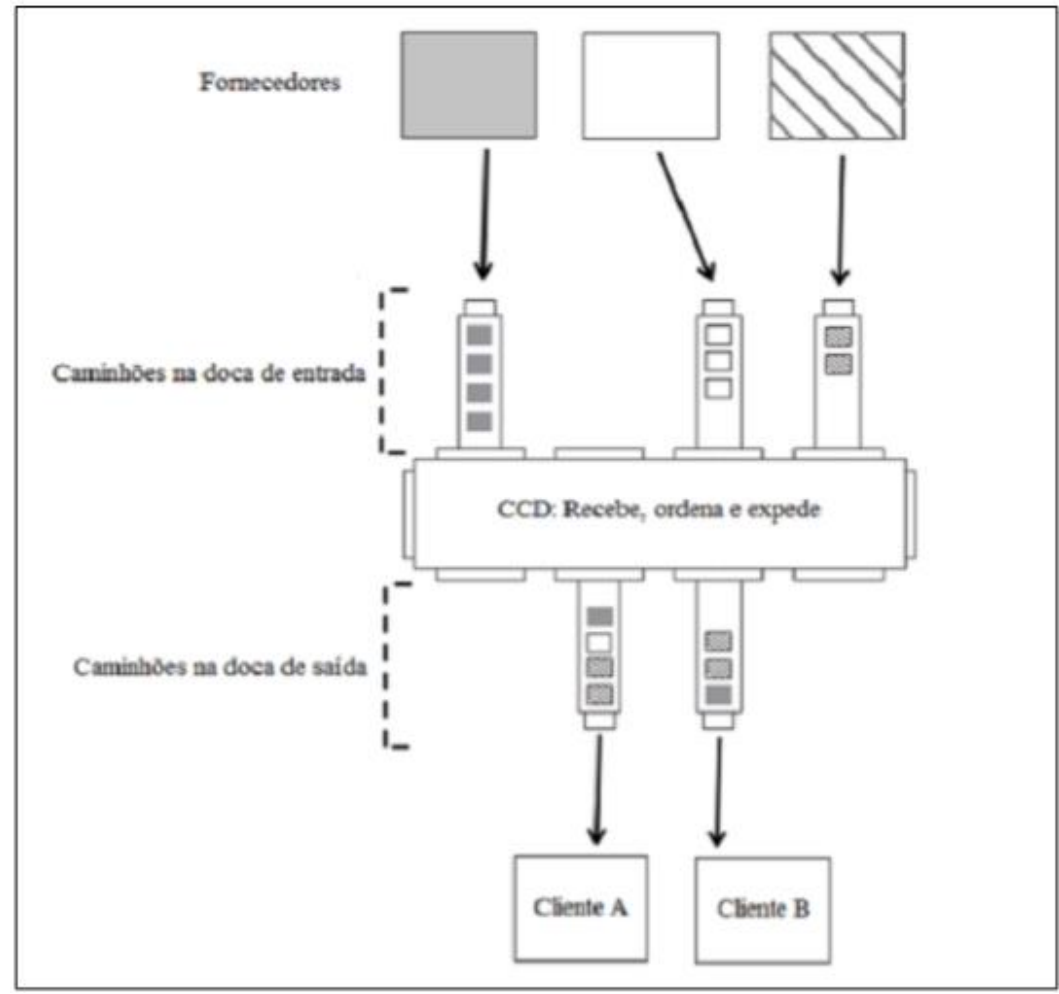

Fonte: Cota (2015, p.5)

\subsubsection{Vantagens e dificuldades}

As vantagens do crossdocking vem desde a diminuição de perda de produto parado, a redução do custo de fretes. Com o produto sempre em movimento e com fornecedores bem alinhados com a demanda produtos não ficam muito tempo na prateleira e nem em armazéns aumentando a satisfação do cliente e diminuindo perdas do processo. Castro, Cassoli e Cota (2019) apontam vantagens da utilização do CDC ligadas aos objetivos de desempenho como segue :

- Melhoria na rapidez, tendo em vista que sem a formação de estoques, as mercadorias são rapidamente realocadas em outros veículos e despachadas ao cliente. Dessa 
maneira o produto não fica parado na prateleira do armazém. O que impacta em custo pois não precisa ser armazenado e não precisa ser coletado posteriormente;

- Aumento da confiabilidade, devido à frequência maior das entregas, evitando falta de produtos em seus estabelecimentos;

- Diante da eliminação da necessidade de armazenagem e coleta do produto, existe impacto direto em sua perecibilidade, trazendo maior qualidade ao produto oferecido;

- No quesito flexibilidade, este método pode auxiliar na flexibilização do mix de produtos, pois devido as entregas frequentes e a alta rotatividade permite uma flexibilidade maior.

Já Segundo EAN International, a utilização do centro de crossdocking traz diversas vantagens para o sistema de distribuição, destacando-se: Redução dos custos de estoque e eliminação dos problemas operacionais de armazenagem e coleta; Redução do custo unitário de transporte, visto que o sistema opera com carga completa ou próxima da capacidade máxima nas carretas; Redução da complexidade de entrega que é realizada de uma só vez com toda a variedade de produtos requerida pelo cliente; Aumento da vida de prateleira do produto, uma vez que ele passará menos ou nenhum tempo em estoque intermediário; Aumento da rotatividade do centro de crossdocking, já que o sistema opera com entregas em menor quantidade e mais frequentes; Redução da falta de estoque nas lojas dos clientes, devido ao ressuprimento contínuo e mais frequente proporcionado pela rede; Redução do estoque total em toda a cadeia de suprimentos, na qual o produto passa a fluir sem ser estocado.

Uma dificuldade desse método é a necessidade de haver uma certa harmonia entre fornecedores e demanda, investimento em uma local apropriado com maquinário apropriado e em dia com a manutenção, sistema de informações sempre funcionando e ativo, a credibilidade dos fornecedores é algo que tem ser levado segundo Cota, Lira e Ravetti. (2014) que aborda de uma formulação matemática para resolver o problema e apresenta uma metaheuristica de resolução.

Segundo Castro, Cassoli e Cota (2019), no Brasil a pratica dos CCDs vem ganhando espaço à medida o conhecimento de seus benefícios se expande e se verifica sua compatibilidade ao modelo de negócios em que se deseja implantá-la, podendo ser verificado em grandes grupos, como: Braspress, Americanas em parceria com Netshoes, Correios. 


\section{Discussões cadeia de suprimento e crossdocking}

Diante do referencial teórico apresentado é pertinente explorar a cadeia de suprimento e os diferentes tipos de centros de crossdocking. Nem todos os centros de crossdocking trabalham da mesma maneira, sendo assim pode ser que diferentes partes da cadeia de suprimento se façam mais importantes diante de cada situação. Iremos apresentar três cenários interessantes e diferentes dentro desse estudo. Cenário normal, cenário com foco no sequenciamento de caminhões no centro, e cenário com foco no roteamento de veículos para visita aos clientes.

\subsection{Cenário com foco no sequenciamento de entrada e saída}

Nesse cenário apenas o centro de distribuição de crossdocking é considerado, assim apenas um dos elementos da cadeia é considerado, a operação em si, como mostrado na Figura 4, e os demais elementos da cadeia continuam fazendo parte da cadeia mas são atividades separada, executadas por outro elo. A responsabilidade aqui é de gestão do CDC. Sendo que a reponsabilidade de entrega no centro é do fornecedor e a responsabilidade de recolhimento no centro é do cliente. As atividade nesse tipo de estudo estão ligadas ao sequenciamento dos caminhões vindos dos fornecedores e os caminhões de entrega aos clientes.

\section{Figura 4- Cadeia de suprimento cenário normal}

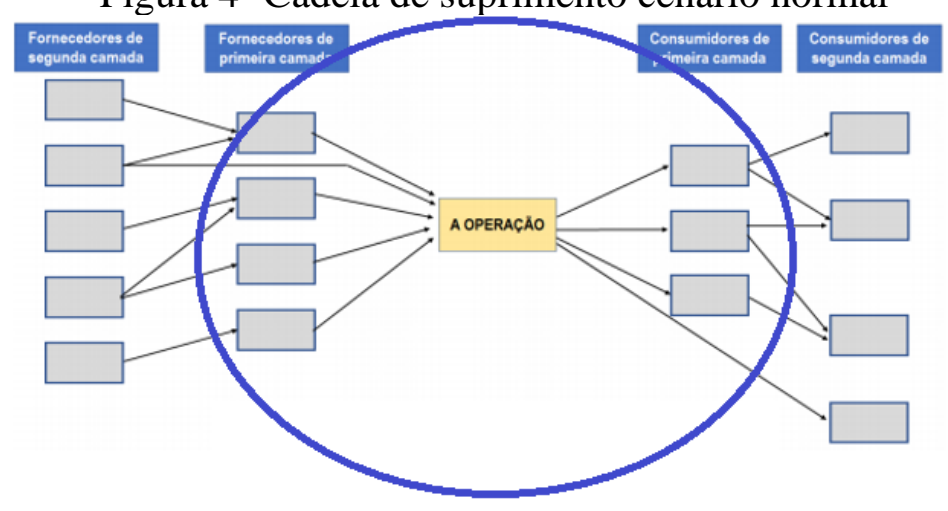

Fonte: Adaptado de Slack, Chambers e Johnston (2009, p. 146)

Pensando no centro de crossdocking como um centro individual do restante da cadeia de produção. Esse centro que tem o objetivo de atender um número considerável de clientes e, para isso, precisa de um número considerável de fornecedores e determinar a ordem em que os caminhões são tratados nas portas é o mais importante isso para evitar material parado dentro do centro e assim garantir estoque reduzido ou nulo, que seria o ideal. Esse tipo de atividade onde apenas o centro é considerado é interessante em situações reais de centro convencionais. 


\subsection{Cenário com foco no sequenciamento de entrada e saída}

Nesse cenário de estudo há consideravelmente mais caminhões de saída do que caminhões de entrada. O número de clientes também é maior que nos outros cenários. Como esse artigo demostra uma vertente pratica ao crossdocking, é interessante pensar aqui em uma empresa de entregas, por exemplo uma empresa do tipo correios. No CDC chegam caminhões carregados, grandes vindos dos centros fornecedores de outros estados. Quando chegam ao CDC esses caminhões são descarregados e as mercadorias carregadas em veículos menores, e esses veículos menores, possuem rotas diferentes todos os dias de forma a atender os cliente, que solicitam algumas vezes entregas únicas, sendo assim as entregas são muitas pois existem vários clientes com demandas pequenas.

Figura 5- Cadeia de suprimento cenário com foco no roteamento de veículos

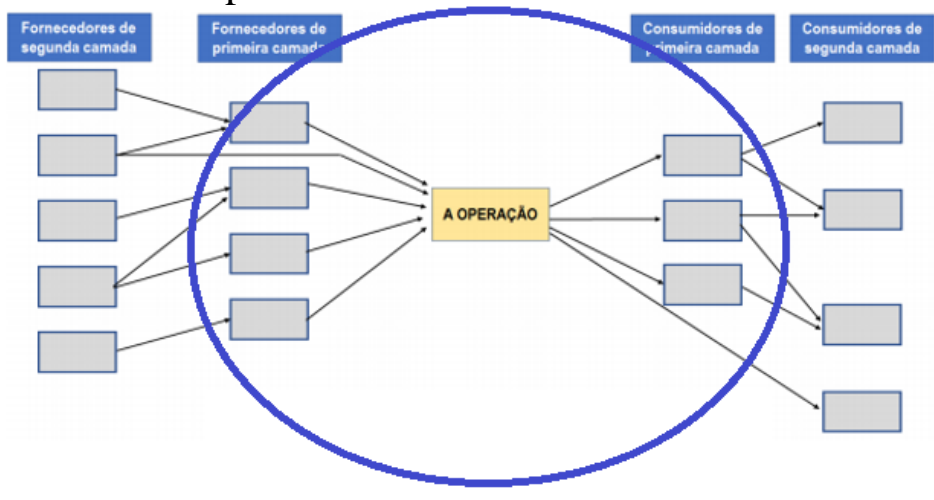

Fonte: Adaptado de Slack, Chambers e Johnston (2009, p. 146)

Esse problema possui um foco pequeno na gestão do sequenciamento de veículos de entrada, as rotas de entrada não se fazem necessárias de serem tratadas, pois cada caminhão possui como destino um CDC. Mas esse cenário possui uma dificuldade maior na cadeia de distribuição. A dificuldade de resolver o problema está no roteamento dos veículos de saída. Um cenário, pensado então para uma transportadora, que faz entregas para muitos clientes e recebe mercadorias vindas de poucos fornecedores. Assim a dificuldade da solução reside em como fazer as entregas e não na ordem de agendamento dos caminhões.

\subsection{Cenário com foco no Sequenciamento de veículos de entrada}


Nesse último cenário a ser tratado, é conveniente pensar em uma rede, contemplando centro de distribuição de crosdocking e clientes diretos, ambos pertencentes a um único dono, como mostrado na Figura 6.

Figura 6- Cadeia de suprimento cenário com foco no sequenciamento de veículos

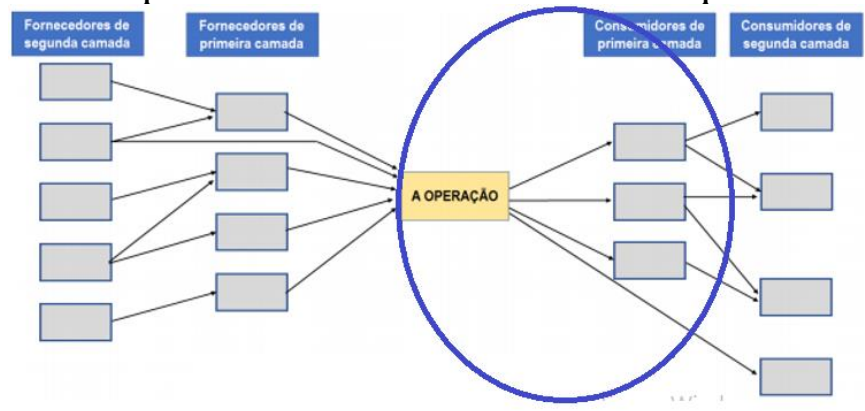

Fonte: Adaptado de Slack, Chambers e Johnston (2009, p. 146)

Nesse caso, para ser prático, objetivo desse artigo, temos como exemplo um grande rede de supermercados, composta por um CDC e as suas filiais que são os supermercados espalhados pelas cidades próximas. Imaginando o CDC ele irá receber caminhões carregados vindo de seus vários fornecedores, esses precisam ser organizados e sequenciados nas docas, o que pode ser difícil, considerando que uma rede de supermercados possui vários fornecedores. Uma vez descarregados os veículos, essas cargas devem combinadas e carregadas em veículos menores com destino a uma das filiais (clientes dessa cadeia produtiva). Nesse cenário, roteamento de entrada não é responsabilidade do CDC, uma vez que cada fornecedor realiza sua entrega, o roteamento dos caminhões de saída é responsabilidade da cadeia entretanto é um roteamento simples, uma vez que temo relativamente pouco cliente (as filiais). Dessa maneira o foco nesse problema é o sequenciamento dos veículos de entrada e saída dentro do centro sem necessidade de preocupação com os problemas de roteamento de veículos.

\section{Considerações Finais}

Diante do artigo apresentado é possível enxergar o centro de crossdocking sob três perspectivas diferentes. Mostrando assim a versatilidade dessa estratégia logística que esta cada dia mais conhecida e aplicada na realidade das organizações. O método do CDC apresentou-se interessante tomando por base a forma como as organizações tem se posicionado no mercado atualmente, afinal, se diferenciar das concorrentes, aumentar a competitividade, oferecer produtos e serviços o mais rápido possível aos clientes, são fatores 
buscados por toda e qualquer organização, e essas condições podem ser alcançadas utilizandose o CDC, uma vez que vantagens estão sendo alcançadas com esse tipo de centro de distribuição.

Entretanto, para que os CDCs possam trazer benefícios é um problema difícil de ser resolvido na prática por envolver um serie de critérios diferente. Existe a necessidade de um estudo criterioso que pode ter focos diferentes. Esse artigo apresentou a perspectiva de três visões diferentes dos centros integrados a cadeia de distribuição, com foco em problemas de sequenciamento e/ou roteamento de veículos. Com isso é possível concluir que os problemas de crossdocking, não são idêntico e não terão uma única vertente a ser tratada, existem configurações diferentes que nos levam a problemas diferentes, sendo assim é um problema ainda nova que possui muito campo para exploração.

\section{REFERÊNCIAS}

Cross docking: How to use the ean - ucc standards.

BALLOU, Ronald H. Gerenciamento da cadeia de suprimentos/logística empresarial / Ronald H. Ballou; tradução Raul Rubenich. - 5. ed. - Porto Alegre : Bookman, 2006.

BOWERSOX, Donald J. et al. Gestão logística da cadeia de suprimentos. 4. ed. Porto Alegre: Amgh, 2014. Tradução de: Luiz Claudio de Queiroz Faria

CASTRO, E. L. B.; CASSOLI, S. P. C. de F; COTA, P. M.; Análise das operações de crossdocking: vantagens e desvantagens no atingimento dos objetivos de desempenho. Coletânea Brasileira de Engenharia de Produção 6-Stellata. , p.25 37, 2019.

COTA, P. M. (2015). Problema de Sequenciamento de Caminhões em Centros de Crossdocking com multiplas docas. Master's thesis, Universidade Federal de Minas Gerais.

COTA, P. M.; LIRA, E. G.; RAVETTI, M. G. O Problema de sequenciamento de caminhões em centros de crossdocking com múltiplas docas In: Simpósio brasileiro de pesquisa operacional, 2014, Salvador.

FARAH JR., Moisés. Os desafios da logística e os centros de distribuição física. Revista FAE Business, n. 02, junho 2002. p. 44-46. Disponível em: <http://files.negociol.com/1829_centros_de_distribuio.pdf $>$. Acesso em: 04 nov. 19.

SLACK, N.; CHAMBERS, S. e JOHNSTON, R. Administração da produção. 3. ed. São Paulo: Atlas, 2009. 
SOUZA, Anali (2010) - Centro de Distribuição. Disponível em: http://fatecid.files.wordpress.com/2010/12/centro-distribuic3a7c3a3o-final-1.pdf. Acesso em: 25/09/2019. 